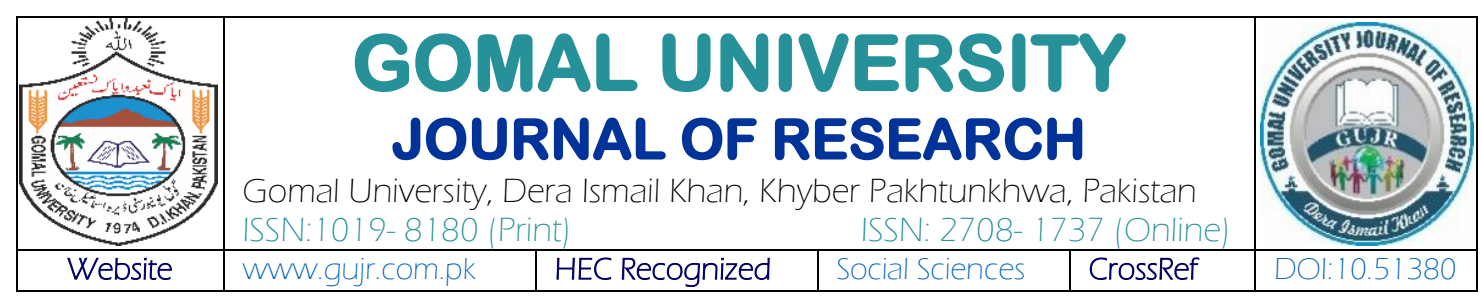

\title{
RELATIONSHIP BETWEEN ACADEMIC STRESS, STUDY HABITS ANDACADEMIC ACHIEVEMENT OF UNDERGRADUATE STUDENTS OF UNIVERSITIES
}

\author{
Mahvish Fatima Kashif', Tahira Mannan² \& Faiza Shaheen³ \\ 'Assistant Professor, Institute of Education, Lahore College for Women University, Lahore, Pakistan \\ 2Visiting Lecturer, Institute of Education, University of Education, Lahore, Pakistan \\ ${ }^{3}$ Assistant Professor, Institute of Education, University of Education Lahore, Faisalabad Campus
}

\section{KEYWORDS \\ Academic Stress, Study \\ Habits, Academic \\ Achievement, \\ University Students}

\section{Article History}

Date of Submission:

03-03-2021

Date of Acceptance:

19-06-2021

Date of Publication:

30-06-2021

\section{ABSTRACT}

It is crucial for students to lessen the academic stress with improving their study habits as they both are important for their academic achievement. Thus, the objective of the research was to explore the relation of academic stress and study habits with academic achievement of undergraduates in universities of Lahore. Research design of study was quantitative approach, followed by correlation research to obtain the objectives. Total population (undergraduate students of education departments), 1721 students; 1214 were from public universities and 507 were from private sector universities. Data was collected by using two questionnaires. The results of research showed that academic stress predicts $54.6 \%$ variance in the academic achievement whereas study habits contribute $53.2 \%$ variation in academic achievement. Results also showed that academic stress has significant but negative relation with academic achievement of students. It was observed that study habit had significant and positive relationship with academic achievement.

\begin{tabular}{|c|c|}
\hline & (c) () \&) 2021 Gomal University Journal of Research \\
\hline Corresponding Author & Mahvish Fatima Kashif: mahvishfatima79@gmail.com \\
\hline $\mathrm{DOl}$ & https://doi.org/10.51380/gujr-37-02-08 \\
\hline
\end{tabular}

\section{INTRODUCTION}

The process of education is not stagnant. It is kept on changing through centuries according to the contemporary demands that society and culture put on it. It is evidenced through history also that certain develop has impact on almost all sections of society including economics (Rao \& Reddy, 2015). The criterion of success is based on efficiency and quality of work these days. The world is demanding and putting youth on the immense challenges. In this regard, in such a scenario, the condition of becoming anxious and feel of anxiety is obvious not only among the higher ups to provide a system but this anxiety can also be observed among teachers, parents and students. According to Sing (2015), academic achievement means the extent to those goals 
and objectives of the education have been met by involving all participants and stakeholders of education system, regardless of any specification of field and discipline (Numan \& Hasan 2017). In this connection, the measurement of academic achievement for university students is done through criterion referenced assessments where students are declared as fail or pass and their results are shown in securing different grade point averages (GPAs) (Nakalema \& Ssenyonga, 2014).

How likely the achievement of students suffers, it has corresponding relationship with tendency of academic stress that is bored by the students (Snehlata \& Ghatol, 2017). Academic stress is such a condition when an individual finds the exceeding expectation commensurate to lacking resources (Alam \& Halde, 2018). Academic stress has also been defined as a body reaction to what is expected by an individual performance (Bakhsh \& Sayed, 2015). According to Aluj and Blanch (2004) study habits are critical variable in predicting academic performance of students. Study habits are defined in different ways by many scholars such as it is said to be the practice that is rendered by an individual student during his or her study program with the purpose of achieving the predetermined goals and objectives (Numan \& Hasan, 2017), it is also meant as the degree of input that student displays during course of study over diverse styles of learning that helps in attaining the desired outcomes (Ozsoy, Memis, \& Temus, 2009). It is not always a matter of ineligibility or lack of intelligence in getting low scores on tests but the factor of bad study habits that hinder the proficient performance of the learners (Menzel, 1982). The practice of healthy study habits is somehow a guarantee towards high outcomes and achievement of the students.

The reciprocal relation of good study habits and high achievement persuade students to adopt better study habits in order to meet challenges of ever-growing system of education (Menzel, 1982). Abid (2006) emphasized on better academic performance that is linked with organized behavioral pattern as well as study habits. Solomon (2013) pointed out an alarming situation of suffering academic achievement due to stress, he added that the physical and mental health also come under dangers of such a stress. Numan and Hasan (2017) gave the view that how academic achievement is linked with getting success in career choice where the undergraduate students are left with no choice behind being at terminal stage towards practical and professional lives. In this connection, it becomes clear that the academic stress harms not only the physical and psychological health and achievement of students but also minimize the career options for the undergraduate students passing out from university studies. In this regard, the academic stress can be overcome and the healthy study habits need to be adopted for improving the academic outcomes and achievements of the students. In this drive, this research study was conducted to highlight relation of study habit, academic stress, with academic achievement of undergraduate students.

\section{Problem Statement}

Stress produces changes in level of academic achievement (Elliot et al., 2005). The academic achievement is not a major factor in choosing educational program for the students but it also affects their selection for jobs (Numan \& Hasan, 2017). Mostly, undergraduate students start their professional life after completing their final degree. Thus academic achievement being an important factor, specially for the undergraduate students it is need of the time to improve the academic achievement of students by lowering their level of academic stress and improving their study habits. So it was needed to find correlation between the variables. Hence, research 
tried to explain relation between academic stress, study habits and academic achievement of undergraduates.

\section{Significance of Study}

This research could be beneficial not only for students to lower down their stress but also for teachers. Teachers could reduce consequences of the academic stress, which may produce severe problems, on the students by giving them proper guidance. This study may help the students to improve their academic achievement by changing their study habits in a better way. In this regard, this research could be road map for students for improving their academic achievement and success, hence may contribute positively not only in lives of students and also for the overall society.

\section{Hypotheses of Study}

$\mathrm{H}_{\mathrm{o}}$ : There is no relationship between academic stress and academic achievement of students. $\mathrm{H}_{\mathrm{o}}$ : There is no relationship between study habits and academic achievement of students. $\mathrm{H}_{\mathrm{o}}$ : There is no difference in perceived academic stress of male and female students. $\mathrm{H}_{0}$ : There is no difference in the study habits of the male and female students.

\section{LITERATURE REVIEW}

Concept of stress originated from the terms woe, misery, torment or ordeal in the 14th century and by end of 17th century Hooke defined stress in relation to physical science. Over that time Lazarus and Folkman (1984) mentioned that stress was categorized into load, stress, and strain. In this connection, the first precise explanation of stress was presented by Selye (1956) as the resemblance among the entire receptions in the body which are adaptable. According to Myers, (2005) stress is an approach applied to recognize and handle the external risky and challenging circumstances. There are three basic models of stress (response based models, stimulus based model and transaction based model) and every model explains stress in the different manner (Papathanasiou, et al, 2015). In this connection, according to Selye (1956) response based models demonstrate stress as response. A usual reaction to stress is called the flight or fight. During it internal secretions are discharged, which activate the sense organs, increase the respiration and pulse rate and stiffen the tissues, as the result of stimulation of nervous system. Consequently, according to Holmes (1978) stimulus based models describe stress as a stimulus which could be one or more life incidences that produce usual or psychiatric responses and increase chances of illness.

Lazarus transaction model focused on cognitive procedure that take place between stimulus and reaction, and elements that affect these procedures (as cited in Papathanasiou et al. 2015). Researchers have studied academic stress on the basis of gender but contradictory findings have been reported. Misra and Castilio (2004) found that both gender have different perception and reaction to stress. Similar results were found in studies of Mazumdar (2012) and Zhang (2014) also found sex difference associated with academic stress. Singh and Upadhyay (2008) explored that female students perceive more academic stress in comparison with male students but in contrast, Zheng, Wan, and Li (2001) reported exactly opposite results. Prabu (2015) explored that students of both gender do not have big difference in perception of the academic stress. According to Mangal (2009) habit is called behavior shown again and again as to be automatic. Habits are the product of experience and practice. Study Habits are dispositions and routine manners adopted for acquisition of knowledge or simply habits practiced for learning (Kumar, 2015). 
Information Processing Approaches: Information processing model of memory provide the basis of this approach which suggests that data is memorized perfectly if it is processed deeply instead of surface level (Marton \& Saljo, 1976). The concept of information processing system was extended by determining three approaches and their sources of motivation: Deep approach, activated when an individual motivate internally and show dedication for the learning; surface approach, stimulated when the person is motivated externally and strategic approach, activated when an individual is motivated for excellent success and does not concern nature of learning (Crede \& Kuncel, 2008). Meta cognitive skill approaches: Capability to change study strategy on basis of demands of learning targets is known as meta cognition and self-regulation ability (Gettinger \& Seibert, 2002). Students high in these adaptive skills are considered distinctive (Zimmerman, 1986). Ford and Kolb's Theories: In motivational systems theory, Ford (1992) measured biological, social and environment effects on achievement. It advises that achievement is affected by motivation, skills, and natural abilities of an individual engaged in a responding environment.

Haseen and Reddy (2014) presented the study of the factors influencing study habits of IX class individuals in Andhra Pradesh. The results showed no significant difference with regard to the factors influencing study habits on basis of gender. Devi and Kumari (2018) recommended that a student lacking effective study habits may not secure high grades despite having abilities of high achievement. Alrefaai, AbdulRab, and Islam (2013) attempted to describe study habits of university students in Saudi Arabia and its relation with their GPA. Results revealed that students mostly study in a disorganized way and they try to fill the gap before exams. Ogoemeka (2013) determined how different factors predict academic performance among Nigerian teachers trainee and concluded that home work and assignment strongly predict academic performance. Mashayekhi, et al. (2014) selected undergraduate students. Results declared that 89\% students have useful study habits and identified positive relation of study habits with academic success. Perception of education as a challenge generates stress that leads to sadness and fearful feeling of deprivation which ultimately result in the poor academic achievement (Misra, \& McKean, 2000).

A research performed by Sun et al. (2013) expressed that the lower academic achievement was strongly linked with elevated level of academic stress. This is similar with results of the study conducted by Li et al. (2007) that adolescents getting unsatisfactory academic achievement and falling at the low hierarchy in their class feel much more academic stress. A study conducted by Bjorkman (2007) among 268 American adolescents demonstrated that GPA and academic stress was inversely related. Liu and Lu (2011) observed negative relation between academic stress and academic achievement of school students. Khan, et al. (2013) investigated influence of academic stress on the performance of students and results showed that academic stress significantly affect performance. In this connection, Alam and Halder (2018) conducted research to estimate relation of academic stress with academic performance of students. Results of study revealed that difference in academic stress on the basis of gender was significant and these two variables were inversely related. Thus academic performance in different forms including grade and position obtained in the exams with respect to fellow students, is alarming due to academic stress.

Khurshid, Tanveer and Qasmi (2012) determined how the study habits of hostellers and day scholars male and female students of public universities of Rawalpindi and Islamabad relate 
with their academic achievement. The statistics revealed that study habits positively relate with academic achievement and girls practice better study habits and achieve the higher grades as compared to boys. Similarly, the day scholars had productive study habits and better academic achievement in comparison with those availing the hostel facilities. Malik and Parveen (2016) selected students showing the high and low academic achievement to determine differences in their study habits and attitudes. Results mentioned that study habits of high and low achievers differ significantly. Thus it is evident from literature that study habits affect student's academic achievement at university level. Similarly above discussed studies showed how important is to minimize academic stress in order to achieve better academic grades which determine future of students either educational or professional, therefore the research tried to explore the relation between academic stress, study habits and academic achievement of the students studying in universities.

\section{Figure 1}

Theoretical Framework of the Study

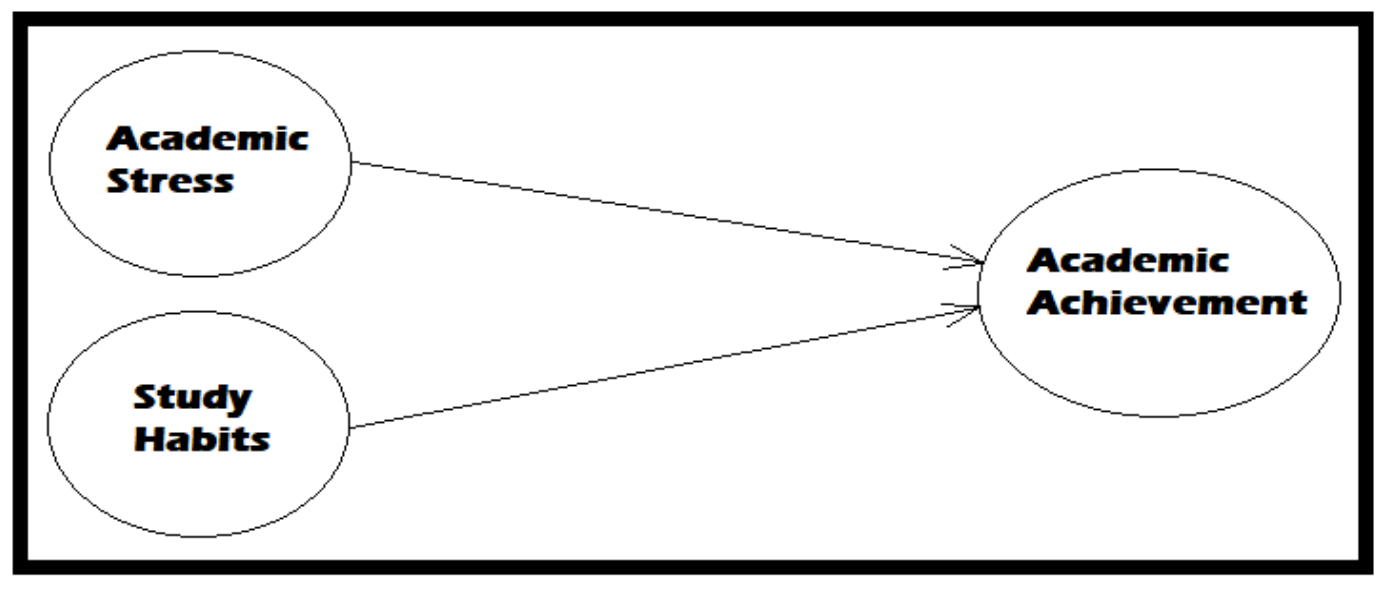

\section{RESEARCH METHDOLODGY}

Using quantitative approach, the correlational design of the research was applied to assess the relationship among research variables; academic stress and study habits (predictors), academic achievement (criterion). Therefore, the study was categorized as quantitative and co-relational research.

\section{Population}

The population is the entire group of elements in which researcher is interested and plan to generalize the results obtained from the sample from entire population. The target population of the research was all the undergraduate students of 4-year degree program of the education departments of all HEC recognized private and public universities in Lahore. Under general category, there were $29 \mathrm{HEC}$ recognized universities in the Lahore (22nd August, 2019). Out of these 29 universities, 10 were public and 19 were private sector universities. The accessible population was the students of the education departments at undergraduate level in selected universities. 
Table 1

Number of Students in Private Universities

\begin{tabular}{ll}
\hline Institutions & Number of students \\
\hline Forman Christian College, LHR. & 120 \\
Lahore Leads University & 20 \\
Minhaj University Lahore & 137 \\
University of Lahore (UOL). & 95 \\
University of Management and Technology, LHR. & 70 \\
University of South Asia & 40 \\
Beacon House National University, LHR. & 25 \\
\hline
\end{tabular}

\section{Sampling}

Proportionate stratified random sampling was utilized to select the sample. Strata were formed on the basis of nature of universities (public/private). Out of 10 public and 19 private sector universities, 4 public and 7 private universities offering education degree at undergraduate level were selected. 30\% students from education departments of both private and public universities were selected randomly as sample. There were total 11 universities with 1721 students enrolled in education departments at undergraduate level. 516 (30\% (1721)) students were taken as sample of research.

\section{Table 2}

\section{Detail of Sample}

\begin{tabular}{lcc}
\hline & Population $(\mathrm{N})$ & Sample $(\mathrm{n})$ \\
\hline Public Universities & 1214 & 364 \\
Private Universities & 507 & 152 \\
\hline Total & 1721 & 516 \\
\hline
\end{tabular}

\section{Data Collection}

Quantitative data were obtained from both the male and female undergraduate students from Lahore's public and private universities. Questionnaires were used by survey method to collect data from participants. They were distributed to respondents and response of each participant was collected on separate questionnaire. To gather the data, the researcher contacted with the students and told them about the objective of the study. The confidentiality of all the students as respondents was ensured by the researcher. The students were asked to review the things correctly and to tick most relevant category. For each student, the demographic information sheet and questionnaires were faced with the plea to answer thoroughly and return it at their easiness.

\section{Instrumentation}

Academic stress inventory developed by Lin and Chen (2009) was employed to measure perceived level of academic stress of students. It contained total 34 items and 7 factors. These factors with their related items were; teachers' stress (Item; 1-9), results stress (10-14), tests stress (15-18), stress due to group study (19-23), stress by peer (24-27), stress of time management (28-30) and self-inflicted stress (31-34). All 34 items were gauged on 5-point Likert-type scale. The level of stress for each factor is determined by score for it, high score indicates more stress (Lin \& Chen, 2009). The study habits inventory questionnaire, consisted of 24 items, developed by Atsuwe and Moses (2017) was administered to understand study habits of undergraduate students. It had 
24 items divided in 4 subscales. 6 items under each factor. SHIQ was measured on 4-point Likert-type scale. Academic achievement of students was measured through CGPA in their last exams.

\section{Reliability of Scales}

Two scales were used to collect data. For academic stress questionnaire designed by Lin and Chen (2009) was used. They have mentioned reliability as 0.90 for over all scale and reliability of factors ranged from 0.85 to 0.92 . It covers 34 items measuring academic stress. Other scale used for study habit was developed by Atsuwe and Moses (2017), containing 24 items under 6 factors. They determined 0.72 value of Cronbach for scale. Cronbach values of reliability for overall scales, academic stress inventory and the study habit inventory questionnaire (SHIQ), was 0.86 and 0.92 respectively and their factors wise reliability were as described below in tables:

\section{Table 3}

Reliability of all Components of Academic Stress Inventory

\begin{tabular}{lccc}
\hline \multicolumn{1}{c}{ Factors } & Cronbach's alpha & No. of items & Position of items in scale \\
\hline Teacher's stress & 0.75 & 9 & $1-9$ \\
Result stress & 0.87 & 5 & $10-14$ \\
Test stress & 0.86 & 4 & $15-18$ \\
Studying in group stress & 0.74 & 5 & $19-23$ \\
Peer stress & 0.84 & 4 & $24-27$ \\
Time management stress & 0.87 & 3 & $28-30$ \\
\hline Self-inflicted stress & 0.86 & 4 & $31-34$ \\
\hline
\end{tabular}

Table 4

Factor wise Reliability of Study Habits Inventory Questionnaire

\begin{tabular}{llll}
\hline Factors & Cronbach Alpha & No. of items & Position of items in scale \\
\hline Homework \& assignments & 0.86 & 6 & $1-6$ \\
Time allocation & 0.81 & 6 & $7-12$ \\
Reading and notes taking & 0.85 & 6 & $13-18$ \\
\hline Teacher consultation & 0.69 & 6 & $19-24$ \\
\hline
\end{tabular}

\section{DATA ANALYSIS}

$\mathrm{H}_{\mathrm{o}}$ : There is no relation between academic stress and academic achievement of the students.

Table 5

Relationship between Academic Stress and Academic Achievement of Students

\begin{tabular}{ccccc}
\hline Model & $\mathrm{R}$ & R Square & Adjusted R Square & Std. Error of Estimate \\
\hline 1 & $.739 \mathrm{a}$ & .546 & .539 & .29147
\end{tabular}

Table 5 presents the result of variance in academic achievement (criterion variable) by academic stress (predictor variable). Here R square 0.546, describes that academic stress predicts 54.6\% variance in academic achievement. Thus academic stress measured for teacher stress (TS), result related stress (RS), test related stress (TTS), study in group stress (SGS), peer stress (PS), time 
management stress (TMS) and the self inflicted stress (SS) produces $54.6 \%$ change in academic achievement.

\section{Table 6}

Results of Multiple Regression Test

\begin{tabular}{clccccc}
\hline Model & & S-Squares & df & M-Square & F & Sig. \\
\hline \multirow{2}{*}{1} & Regression & 51.850 & 7 & 7.40 & 87.189 & $.000 \mathrm{~b}$ \\
& Residual & 43.157 & 508 & .08 & & \\
\hline & Total & 95.008 & 515 & & & \\
\hline
\end{tabular}

Table 6 describes good fit of the model. It shows that p-value for this model is .000 $<.05$ at .05 level of significance which indicates that academic stress is significantly related with academic achievement.

\section{Table 7}

Results of Multiple Regression Analysis for Coefficients

\begin{tabular}{lccccc}
\hline & Unstandardized & Coefficients & Standardized & t & Sig. \\
& $\mathrm{B}$ & SE & Coefficients Beta & & \\
\hline (Constants) & 3.863 & .080 & & 48.286 & .000 \\
Teacher's stress (TS) & .008 & .003 & .102 & 3.124 & .002 \\
Result stress (RS) & -.038 & .005 & -.540 & -7.979 & .000 \\
Test stress (TTS) & -.014 & .006 & -.150 & -2.254 & .025 \\
Study in group stress (SGS) & -.007 & .003 & -.067 & -2.026 & .043 \\
Study in group stress (PS) & -.014 & .006 & -.157 & -2.241 & .025 \\
Time management stress (TMS) & .016 & .005 & .141 & 3.159 & .002 \\
\hline Self-inflicted stress (SS) & -.001 & .005 & -.009 & -.140 & .889 \\
\hline
\end{tabular}

Table 7 explains contribution of predictor variables (factors) for criterion variable. Beta values for RS, TTS, SGS, PS and SS predictors are negative which shows negative correlation between predictors and academic achievement, while positive beta values for TS and TMS show positive correlation with academic achievement. Here, p- values for TS is .002 $<.05$, for RS is .000 $<$ .05 , for TTS is .025<.05, SGS is .043<.05, for PS is $0.025<.05$ and for TMS is .002 $<.05$ which indicate that predicting variables significantly predict academic achievement (criterion variable).

$\mathrm{H} \mathrm{o:} \mathrm{There} \mathrm{is} \mathrm{no} \mathrm{relation} \mathrm{between} \mathrm{study} \mathrm{habits} \mathrm{and} \mathrm{academic} \mathrm{achievement} \mathrm{of} \mathrm{students.}$

\section{Table 8}

Relationship between Study Habits and Academic Achievement of Students

\begin{tabular}{ccccc}
\hline Model & $\mathrm{R}$ & R Square & Adjusted R Square & Std. Error of Estimate \\
\hline 1 & $.730 \mathrm{a}$ & .532 & .529 & .29486 \\
\hline
\end{tabular}

Predictors: (Constants), TC, TA, HA, RN

Table 8 represents the results of variance in academic achievement due to study habits. Results show that study habits contribute $53.2 \%$ variation in the academic achievement. Thus study habits, measured for the homework and assignments (HA), time allocation (TA), reading and 
notes taking ( $\mathrm{RN}$ ) and the teacher consultation (TC) produces $53.2 \%$ changes in the academic achievement.

\section{Table 9}

\section{Multiple Regression Test Result}

\begin{tabular}{llccccc}
\hline Model & & S-Squares & df & M-Square & F & Sig. \\
\hline 1 & Regression & 50.579 & 4 & 12.64 & 145.432 & $.000 \mathrm{~b}$ \\
& Residual & 44.429 & 511 & .08 & & \\
\hline
\end{tabular}

Table 9 explains how good model fits. It is given that p-value for this model is .0oo $<.05$ (level of significance) that show that study habits of undergraduates significantly related with academic achievement.

\section{Table 10}

\section{Results for Coefficients}

\begin{tabular}{llccrrr}
\hline Model & & Unstandardized & Coefficients & Standardized & $\mathrm{t}$ & Sig. \\
& & $\mathrm{B}$ & SE & Coefficients Beta & \\
\hline 1 & (Constant) & 1.756 & .064 & & 27.459 & .000 \\
& Homework \& ssignment (HA) & .025 & .005 & .247 & 4.766 & .000 \\
& Time allocation (TA) & .025 & .005 & .224 & 5.114 & .000 \\
& Reading \& notes taking (RN) & .021 & .007 & .201 & 3.238 & .001 \\
\hline & Teacher consultation (TC) & .015 & .004 & .162 & 3.524 & .000 \\
\hline
\end{tabular}

Table 10 expresses contribution of the predictor variables (factors) for the criterion variable. In this connection, Beta values for all factors are positive which represent that all these factors positively relate with academic achievement. Results also show that p-values for HA, TA, RN and TC factors are .000 $<.05$, .000 $<.05$, .001 $<.05$ and .000 $<.05$ (level of the significance) respectively which thus indicate that all these factors significantly related with the academic achievement.

$\mathrm{H}_{\mathrm{o}}$ : There is no significant difference in level of academic stress of male and female students.

\section{Table 11}

Gender Based Difference in Academic Stress

\begin{tabular}{llcccccc}
\hline Academic Stress & Gender & $\mathrm{N}$ & Mean & SD & t & df & Sig(2-tailed) \\
\hline & Male & 106 & 99.80 & 23.55 & -1.979 & 179.401 & .049 \\
\hline & Female & 410 & 105.01 & 26.39 & & & \\
\hline
\end{tabular}

The gender based hypothesis was examined and the table 11 presents that t- value is $1.979>$ 1.96 with p-value $0.049<.05$ (level of significance) which shows that female and male students have different levels of academic stress. Therefore, It is also evident that female experience more academic stress than male undergraduates as mean value for female is 105.01 while for male is 99.80 .

$\mathrm{H}_{\mathrm{o}}$ : There is no significant difference in the study habits of male and female undergraduate students. 
Table 12

Comparison of Male and Female Students for Different Factors of Study Habits

\begin{tabular}{lllllcll}
\hline Study Habits & Gender & $\mathrm{N}$ & Mean & SD & t & df & Sig. \\
\hline Home Work \& Assignments & Male & 106 & 16.69 & 4.77 & -3.660 & 143.301 & .000 \\
& Female & 410 & 18.53 & 3.90 & & & \\
Time Allocation & Male & 106 & 14.68 & 4.25 & -5.284 & 148.464 & .000 \\
& Female & 410 & 17.07 & 3.69 & & & \\
Reading \& Notes taking & Male & 106 & 17.27 & 4.61 & -1.282 & 146.435 & .202 \\
& Female & 410 & 17.90 & 3.91 & & & \\
Teacher consultation & Male & 106 & 18.09 & 6.58 & .671 & 127.082 & .503 \\
\hline & Female & 410 & 17.64 & 4.12 & & & \\
\hline
\end{tabular}

Table 12 shows the difference between the different study habits of male and female students. Here t-value for home work and assignments (HA) and time allocation (TA) factors is $3.660>$ 1.96 and $5.284>1.96$ with p-values .000 $<.05$ and .000 $<.05$ (significance level) which expresses significant difference in study habits of male and female students with these dimensions. Mean values for female for these factors are 18.53 and 17.07 which are greater than mean values; 16.69 and 14.68 for male students. Thus, mean values of male and female undergraduates for these factors show that female perform better than male students for HA and TA. For reading and notes taking and teacher consultation factors, p-values are .202>.05 values and $.503>.05$, at .05, so, the male and female undergraduate students do not differ for these factors of study habits.

\section{DISCUSSION}

The results showed that academic stress have significant but negative relation with academic achievement of students. Students who scored higher on academic stress scale were unable to show good academic achievement. The findings of the study were similar to Bjorkman (2007), Liu and Lu (2011) and Mishra (2017) who also explored negative relation between academic stress and academic performance. Alam and Halder (2018) and Li et al. (2007) also found that highly stressed students scored lesser marks while less stressed students scored higher marks in their examination. In this connection, results of multiple regression analysis pointed out that study habits had significant positive relation with academic achievement of undergraduates. This result was same as discussed in the another research conducted by Rabia et al. (2017) in Pakistan. The studies conducted by Ergene (2011) and Mashayekhi et al. (2014) also showed that study habits and Grade Point Average (academic achievement) had positive relation. Thus, the results of present study were difference from results of research by Amuda and Ali (2018). Hence, they observed that study habit patterns did not relate significantly with the academic performance.

It was also examined that how the academic stress vary with gender and results revealed that female undergraduates feel higher level of academic stress as compared to male. This finding was in accordance with results of research conducted by Busari (2012). On contrary, Zheng et al. (2001) observed that the male students perceived more academic stress than females while Prabu (2015) reported that academic stress did not significantly with genders. Study habits of male undergraduates differ significantly from female undergraduates. Khan (2016) also found that study habits changed significantly for the different gender but Haseen and Reddy (2014) reported that boy and girl students did not vary significantly in their study habits. In the study, 
female students were well again than male not only in the overall study habits but also along homework and assignments and time allocation factors. Another study established in Lahore (Pakistan) by Numan and Hasan (2017) also evaluated that female university undergraduates had better study habits than male undergraduates. Research conducted by Khurshid, Tanveer and Qasmi (2012), thus, outside of Pakistani context, also reported similar findings. Ogoemeka (2013) reported that girls performed better than the boys for the home work and assignment predictor.

Khanam et al. (2017) conducted a study on the university students to observe the general time management of students for studies and they concluded that the gender had no effect on time management habit of students. For reading and notes taking and teacher consultation factors, no significant gender difference was found. Similarly, Abay et al. (2015) study also revealed the insignificant difference in reading and notes taking habits of the male and female whereas the results from the study of Gudaganavar and Halayannavar (2014) pointed out that boys and girls differ significantly for reading and notes taking habits. Wilson (2012) found in their study that that males were statistically different from females with respect to meeting their instructor out of class.

\section{CONCLUSION}

Researchers mostly focused on relationship between academic achievement and overall stress faced by students in their lives either at home or in school whereas relation between academic stress and academic achievement was comparatively less studied. Most researchers worked on study habits at school level and comparatively lesser work was available on the study habits at university level in Pakistan. So, it was needed to understand study habits and its relation with academic achievement of students studying in universities. Thus, research aimed to determine the relation of academic stress and study habits with academic achievement of the university undergraduates. It was concluded from the results that academic stress and study habits of undergraduates were significantly related to their academic achievement. Academic stress was negatively related to academic achievement while study habits show positive link with academic achievement.

It was shown that six factors of the academic stress; teacher's stress, test stress, result stress, studying in group stress, peer stress and time management stress were significantly related with the academic achievement whereas the self-inflicted factor of the academic stress was not significantly related to the academic achievement. All factors of study habits; reading and note taking, homework and assignments, time allocation, and teacher consultation had significant and positive relation with academic achievement. It was also revealed that male and female undergraduates significantly differ in academic stress and it was evident that female students were experiencing more academic stress than the male students. It was also evident that male students significantly differ from female participants in their study habits. Female students were well again in study habits and specifically in doing home work and assignments and in time allocation but both had almost similar habits of reading and notes taking and teacher consultation.

\section{Recommendations}

The results of the study indicate that academic stress hinder good academic achievement of undergraduate students whereas good study habits improve their academic achievement, so it 
is important to take some steps to reduce their academic stress so they become useful members of society.

1. Universities should arrange counseling programs to explore the causes of academic stress and develop strategies to minimize them. Therefore, departments could arrange lecturers by trainers, mentors and motivational speakers to lower down the students' academic stress.

2. Co-curricular activities like healthy games, outdoor trips, art and craft exhibitions and other healthy competitions could also be arranged by departments to relax the mind of students.

3. Universities and departments should arrange seminars to highlight and nurture the good study habits among the students along with their importance and strategies to adopt them.

4. Teacher consultation is an important study habit followed by high achievers so teachers should allow and inspire students to ask their queries other than lecture time to upgrade knowledge.

5. As results showed that male students give less importance to homework and assignments and time allocation so qualitative study including the interviews of such students in different contexts may be arranged for the deeper understanding of this behavior of male students.

\section{REFERENCES}

Abay, A., Mebrahtu, A., Adamu S., \& Hagos y. (2012). Gender difference on factors affecting academic achievement: The case of general secondary school students of Aksum town. International Journal of Academic Research in Education and Review, 3(7), 178-196.

Abid, H. C. (2006). Effect of guidance services on study attitudes, study habits and academic achievement of secondary school students. Bulletin of Education and Research, 28(1),

Alam, K., \& Halder, U. K. (2018). Academic stress and academic performance among higher secondary students: A gender analysis. International Journal of Creative Research Thoughts, 6(1), 687-692.

Alrefaai,I., Abdul, S., \& SaifulIslam, M. (2013). The General study habits of major EFL students in King Khalid University and their relationships with GPA, gender and certain Social factors. Umm al-Qurma University Journal of Languages and Literature, 10, 10-63.

Aluja, A., \& Blanch, A. (2004). Socialized personality scholastic aptitudes, study habits and academic achievement: Exploring the link. European Journal of Psychological Assessment, 20(10), 1-9.

Amuda, B. G., \& Ali, D. G. (2018). Relationship among study habits, gender, marital status, age, parents' level of education and academic performance of NCE students in Kashim Ibrahim college of education Maiduguri, Borno state, Nigeria. International Journal of Education, Learning and Development, 6(4), 78-89.

Atsuwe, B. A., \& Moses, N. I. (2017). Influence of study habits on the academic performance of physics students in Federal University of Agriculture Makurdi, Nigeria. International Journal Education. Studies, 4(2), 25-35.

Bakhsh, M. M., \& Sayed, S. A. (2015). Sources of academic stress: Stress management among regular and executive MBA students. International Journal of Endorsing Health Science Research, 3(1), 17-22. 
Bjorkman, S. M. (2007). Relationships among academic stress, social support, and internalizing and externalizing behavior in adolescence (Degree: Doctor of Philosophy, Northern Illinois University).

Busari, A. O. (2012). Identifying difference in perceptions of academic stress and reaction to stressors based on gender among first year university students. International Journal of Humanities and Social Science, 2(14), 138-146.

Crede, M. R., \& Kuncel, R. (2008). Study habits, skills and attitudes, the third pillar supporting collegiate academic performance. Perspectives on Psychological Science, 3(6), 425-453.

Devi, S., \& Kumari, A. (2018). To measure the effect of gender on the study habits of students of jawahar narodaya vidyalayas in Haryana. International Journal of Research, 5(7), 2898-2908.

Elliot, A. J., Shell, M. M., Henry, K. B., \& Maeir, M. A. (2005). Achievement goals, performance contingencies, and performance attainment: Experimental test. Journal of Educational Psychology, 97(4), 630-640.

Ergene, T. (2011). The relationships among test anxiety, study habits, achievement, motivation, and academic performance among Turkish high school students. Education and Science, 36(160), 320-330.

Gettinger, M., \& Seibert, J. K. (2002). Contributions of study skills to academic competence. School Psychology Review, 31(3), 350-365.

Goldfinch, J., \& Hughes, M. (2007). Skills, learning styles and success of first-year undergraduates. Active Learning in Higher Education, 8(3), 259-273.

Gudaganarar, N. V., \& Halayanava, R. B. (2014). Influence of study habits on academic performance of higher primary school students. International Journal of Science and Research. 3(2), 277- 280

Haseen, S., \& Reddy, L. K. (2014). A study of factors influencing study habits of ix class students in renigunta mandal, Andhra Pradesh. International Multidisciplinary $e-$ Journal, 3(1), 9046-9051.

Holmes, T. S. (1978). Life situations, emotions, and diseases. Psychosomatics.19(12), 747-54. doi: 10.1016/So033-3182(78)70891-1

Khanam, N., Sahu, T., Rao, E. V., Kar, S. K., \& Quazi, Z. S. (2017). A study on university student's time management and academic achievement. International Journal of Community Medicine and Public Health, 4(12), 4761-4765.

Khursid, F., Tanveer, A., \& Qasmi, F. N. (2012). Relationship between study habits and academic achievement among hostel living and day scholars' university students. British Journal of Humanities and Social Science, 3(2), 34-42.

Kumar, S. (2015) Study habits of undergraduate students. International Journal of Education and Information Studies. 5(1), 17-24.

Lazarus, R. S., \& Folkman, S. (1984). Stress, appraisal, and coping. New York: Springer publishing company.

Li, J. H., Feng, X. L., Mei, S. L., \& Yao, D. L. (2007). Investigation of study pressure effects on mental health of junior high school students in Changchun. Medicine Society, 20(2), 56-57.

Lin, Y. M., \& Chen, F. S. (2009). Academic stress inventory of students at universities and colleges of technology. World Transactions on Engineering and Technology Education, $7(2), 157-162$.

Liu, Y. Y., \& Lu, Z. (2011). The Chinese high school student's stress in the school and academic achievement. Educational Psychology, 31(1), 27-35. 
Malik, M., \& Parveen, N. (2016). Study habits and academic achievement: a comparative analysis of the high and low academic achievers. Bahria Journal of Professional Psychology, 15(2), 81-94.

Marton, F., \& Saljo R. (1976). On qualitative differences in learning: I-outcome and process. British Journal of Educational Psychology, 46(1), 115-127..

Mashayekhi, et al. (2014). The relationship between the study habits and the academic achievement of students in Islamic Azad University of Jiroft branch. International Journal of Current Research and Academic Review, 2(6), 182-187.

Mazumdar, H., Gogoi, D., Buragohainand L., \& Haloi N. (2012). A comparative study on stress and its contributing factors among the graduate and postgraduate students. Advances in Applied Science Research, 3(1), 399- 406.

Menzel, W. E. (1982). How to study effectively. London: Oxford University Press.

Mishra, M. (2017). Effect of academic stress on academic achievement of college students. International Research Journal of Human Resources and Social Sciences, 4(11), 261-274.

Misra, R. \& McKean, M. (2000). College students' academic stress and its relation to their anxiety, time management, and leisure satisfaction. American Journal of Health Studies, 16(1), $41-51$.

Misra, R., \& Castillo, L.G. (2004). Academic stress among college students: Comparison of American and international students. International Journal of Stress Management, 11(2), 132-148.

Myers, D. G. (2005). Stress and Health (6th ed.). New York: Worth Publishers.

Numan, A., \& Hasan, S. S. (2017). Effect of study habits on test anxiety and academic achievement of undergraduate students. Journal of Research and Reflections in Education, 11(1), 1-14.

Ogoemeka, H., O. (2013). Study Habits Skills Components as Predictors of Academic Performance among Teachers Trainee in Nigeria. International Journal Educational Research, 1(1), 34-39.

Ozsoy, G., Memis, A., \& Temur, T. (2009). Metacognition, study habits and attitudes. International Electronic Journal of Elementary Education, 2(1), 154-166.

Papathanasiou, I. V., Tsaras, K., Neroliatsiou, A., \& Roupa. A. (2015). Stress: Concepts, theoretical models and nursing interventions. American Journal of Nursing Science, 4(2), 45-50.

Prabu, S. P. (2015). A study on academic stress among higher secondary students. International Journal of Humanities and Social Science Invention, 4(10), 63-68.

Rao, K. V., \& Reddy, S. V. (2015). Effect of study habits, mental health and academic stress on academic achievement among teacher trainees psychology. Indian journal of Research, 4(6), 471-473.

Selye, H. (1956). The stress of life. New York: McGraw-Hill Book Company.

Singh, A., \& Upadhyay, A. (2008). Age and sex differences in academic stress among college students. Social Science International, 24(1), 78-88.

Singh, S. K. (2015). Mental health and academic achievement of college students. The International Journal of Indian Psychology, 2(4), 2349-3429.

Solomon, O. (2013). Exploring the relationship between resilience, perceived stress and academic achievement (Degree of master of science, Graduate College of the Oklahoma State University). 
Sun, J. D., Dunne, M. P., Hou, X. Y., \& Xu, A. Q. (2011). Educational stress scale for adolescents: Development, validity, and reliability with Chinese students. Journal of Psycho educational Assessment, 29(6), 534-546.

Zhang, P. (2014). Investigation and analysis on secondary school students' academic pressure. Journal of Educational Institute of Jilin Provence, 30(02), 84-86.

Zheng, L. K., Wan, L. P., \& Li, Z. Q. (2001). Effects of learning pressure on psychosomatic health of primary and secondary school students. Chinese Journal of School Health, 22(3), 224-225.

Zimmerman, B. J. (1986). Becoming a self-regulated learner: Which are the key sub-processes? Contemporary Educational Psychology, 11(4), 307-313. 